\section{Effects of rearing on homosexual behavior in the male laboratory rat*}

\author{
JOHN A. ALLEN and ROBERT BOICE \\ University of Missouri, Columbia, Mo. 65201
}

Thirty-six male laboratory rats were raised in one of three conditions: social isolation, sexual segregation, or cohabitation with females. Male interlopers introduced into the individual cages of adults elicited the most mounting and thrusting in isolates. Analysis of concomitant social behaviors suggests that the mounting functioned as a component of dominance processes; offensive postures and mounts correlated significantly in the group raised as isolates.

Segregation of the sexes may be a prime factor in the etiology of animal homosexuality. Avery (1925) and Loutitt (1927) found homosexual mounts common in male guinea pigs caged together. Segregated male laboratory rats were reported to "attempt a complete copulatory act" prior to heterosexual intercourse (Stone, 1922, p. 123). Mounting of male interlopers occurs after segregated raising (Grant, 1963) and in groups of male wild rats (Barnett, 1958).

Jenkins (1928) hypothesized that male rats segregated at an early age came to prefer-a homosexual stimulus. She found that segregation before puberty did produce more approaches over an electrified grid to males than to estrous females. Beach (1942a) found that males segregated at 21 days of age performed poorly in heterosexual tests of copulation compared to rats raised in isolation or in cohabitation with females. Interestingly, rats segregated with females were only intermediate to isolates.

In general, however, the literature is contradictory about this point. Folman \& Drori (1965) corroborated Beach's findings only in part and obtained contradictory results in two comparable studies. Gerall, Ward, \& Gerall (1967) found no significant difference between copulatory ability of male rats raised in segregation or cohabitation.

Even though Beach (1942a) found isolated males to be better copulators than those raised socially, there is reason to expect isolation to have the opposite effect. For example, Drori \& Folman (1967) and Gerall, Ward, \& Gerall (1967) found isolated males to be significantly inferior copulators compared to socially raised males. One

\footnotetext{
* Based on a thesis submitted by the first author to the Graduate School, University of Missouri, in partial fulfillment of requirements for the MA degree, 1970. The authors thank Dr. D. C. Wright for his helpful advice. Send reprint requests to $R$. Boice, Department of Psychology, 209 McAlester Hall, University of Missouri, Columbia, Mo. 65201 .
}

problem is that homosexuality must often be inferred from poor performance in heterosexual copulation. Even where homosexual activity has been observed (Beach, $1942 \mathrm{~b})$, details are omitted.

In general, homosexual behaviors remain ignored and ill-defined, even though they are "... known to occur in practically every species of mammal which has been extensively studied [Kinsey, Pomeroy, Martin, \& Gebhard, 1953, p. 448]." Male homosexuality in the absence of "appropriate" sexual objects is reported only briefly in swine (Hafez, Sumption, \& Jakway, 1962), dogs (Fuller \& Dubois, 1962), rabbits (Brown, 1937), and rhesus monkeys (Kempf, 1917).

The purpose of the present study was to compare effects of three rearing conditions, isolation, sexual segregation, and cohabitation with females, on subsequent social and sexual behaviors toward interlopers. Emphasis was directed at relationships between homosexual behaviors and other social/agonistic behaviors. SUBJECTS

The Ss were 36 male offspring selected from litters of nine Sprague-Dawley mothers "time-mated" by the supplier. Those raised in group conditions were housed in Wahmann suspended cages, $40 \times 12 \times 12 \mathrm{~cm}$, with mesh floors and fronts. Isolates were housed in individual Wahmann cages, $20 \times 24 \times 18 \mathrm{~cm}$. All had free access to Lab Blox and water. A reversed 12-h light cycle was maintained in the colony throughout.

\section{PROCEDURE}

At 21 days of age, 36 males were weaned and assigned by split-litter technique to one of three rearing conditions: social isolation, monosexual segregation, or cohabitation with females. Each of 12 males in the cohabitation condition shared a cage with three females of the same age. Segregated males were housed in three cages, each containing four Ss.

At 85 days of age, all Ss were transferred to clean individual cages.
Testing began at 90 days of age. Testing took place during the dark phase of the light cycle, under dim illumination from a $25 \mathrm{~W}$ red light bulb. In each of 10 days, a stimulus male (interloper) of the same age was introduced into the home cage of each resident rat for $15 \mathrm{~min}$. The three stimulus males were marked on their flanks and backs. They were presented in rotating order to prevent two consecutive uses of the same animal. The order in which residents were tested was randomized daily.

Frequency measures were recorded for a variety of social acts and postures exhibited by residents: ano-genital sniffs, aggressive grooms, displacement grooms, offensive postures (sideways and upright), elevated crouches, and mounts (after Grant \& Mackintosh, 1963).

\section{TESULTS}

. The percentages of Ss that mounted an interloper at least once during the 10 tests were $50,16.6$, and 8.3 for the isolation (I), segregation (S), and cohabitation (C) conditions, respectively. Group differences in mounting of stimulus animals were statistically reliable (Table 1 ).

Significant differences between groups were also found in frequency of ano-genital sniffing ( $\mathrm{C}$ males highest and I males lowest) and defensive postures $(\mathrm{C}>\mathrm{I}>\mathrm{S})$. Group differences were not reliable for aggressive grooms, displacement grooms, offensive postures, and elevated crouches (Table 1 ).

Table 2 is an analysis of mounts by days. There was no systematic increase or decrease in mounts over the 10 days of testing.

Spearman rank correlation coefficients were computed between all possible pairs of behavioral measures in Group 1 (Table 3). Significant correlations were obtained between mounts and offensive postures and between elevated crouches and displacement grooms. DISCUSSION

This study suggests a significant influence of early social isolation on adult homosexual behavior. Males raised in isolation mounted interloping males more of ten than did males raised in sexual segregation or cohabitation with females. Within Group 1, the typical pattern of the homosexual behavior sequence is reflected in the positive correlation between offensive postures and mounts.

A typical behavior pattern of homosexual mounting was evident. In those encounters involving more than one mount, each mount was commonly preceded by this sequence: Initial mounts occurred between 2 and $12 \mathrm{~min}$ (mode $=5 \mathrm{~min}$ ) after introduction of the interloper. The 
Table 1

Sociosexual Behavior in Groups of Rats Raised in Isolation (I), Sexual Segregation (S), or Cohabitation With Females (C) Over All 10 Days. One-way analysis of variance was used to test significance (F) between groups.

\begin{tabular}{|c|c|c|c|c|}
\hline & \multicolumn{3}{|c|}{ Mean Group } & \multirow{2}{*}{$\begin{array}{c}F \\
(d f=2,33)\end{array}$} \\
\hline & I & $\mathbf{S}$ & C & \\
\hline Ano-Genital Sniffs & 56.0 & 70.6 & 73.9 & $3.49 *$ \\
\hline Aggressive Grooms & 19.8 & 26.7 & 32.3 & 2.06 \\
\hline Displacement Grooms & 22.0 & 20.8 & 20.5 & $<1$ \\
\hline Offensive Postures & 4.6 & 7.3 & 4.8 & $<1$ \\
\hline Defensive Postures & 9.5 & 5.2 & 11.0 & $3.59 *$ \\
\hline Elevated Crouches & 3.0 & 5.5 & 6.5 & 2.03 \\
\hline Mounts & 8.5 & 1.3 & 1.8 & $2.70^{*}$ \\
\hline
\end{tabular}

$*_{p}<.05$

Table 2

Mounts by Days for Rearing Condition Groups

\begin{tabular}{llcccccccccc}
\hline & & \multicolumn{10}{c}{ Test Days } \\
\cline { 3 - 11 } & & 1 & 2 & 3 & 4 & 5 & 6 & 7 & 8 & 9 & 10 \\
\hline \multirow{3}{*}{ Isolation } & Mean & .91 & .83 & .66 & .41 & .75 & 1.10 & .58 & 1.08 & .33 & .50 \\
& SD & 1.70 & 1.67 & 1.10 & .75 & 1.36 & 1.41 & 1.11 & 1.70 & .84 & .95 \\
Segregation & Mean & - & .16 & .08 & .16 & .25 & .25 & .08 & - & .08 & - \\
& SD & - & .36 & .26 & .54 & .59 & .82 & .26 & - & .26 & - \\
Cohabitation & Mean & .41 & - & - & .16 & .33 & .33 & - & - & .25 & - \\
& SD & 1.37 & - & - & .54 & 1.10 & 1.10 & - & - & .82 & - \\
\hline
\end{tabular}

Table 3

Intercorrelations Among Sociosexual Behaviors of Rats. Raised in Isolation $(N=12)$

\begin{tabular}{lcccccc}
\hline & (b) & (c) & (d) & (e) & (f) & (g) \\
\hline Ano-Genital Sniffs (a) & .15 & .36 & -.14 & .38 & .36 & .19 \\
Aggressive Grooms (b) & - & .05 & .37 & -.08 & .09 & .07 \\
Displacement Grooms (c) & - & - & .07 & -.07 & $.62^{*}$ & .02 \\
Offensive Postures (d) & - & - & - & .32 & -.05 & $.64^{*}$ \\
Defensive Postures (e) & - & - & - & - & .03 & .33 \\
Elevated Crouches (f) & - & - & - & - & - & .06 \\
Mounts (g) & - & - & - & - & - & - \\
\hline
\end{tabular}

$* p<.05$

resident always initiated the behavioral sequence. Repeated instances of aggressive grooming of the interloper were interspersed with offensive posturing by the resident. Successive attacks culminated in mounting, with thrusts and palpitations, of ten felling the interloper. The interloper reacted with squeals and attempts at flight. Postcopulatory grooming was not consistently present, although it occurs reliably following heterosexual mounts (Grant \& Mackintosh, 1963).

Perhaps the explanation of effects of social isolation should focus on isolation as a stressor. Stress, as a factor in producing homosexuality, has been suggested elsewhere. Calhoun (1962) reported widespread homosexuality in an overcrowded "behavioral sink," Logan \& Boice (1969) found homosexual mounting following shock termination in a stressful situation, where elicited aggression inhibited an adaptive avoidance response. The appearance of homosexual mounting in the elicited aggression context also suggests a role for social dominance; a dominant male rat shows sexual responses during an encounter with a subordinate male rat (Reynierse, in press). In the present study, offensive postures and mounts were significantly correlated in Group 1. An interloper with its tendency to be submissive is apparently a good releaser for mounting when the males are at least somewhat domesticated (Barnett \& Stoddart, 1969). Interlopers in the present study displayed only submissive postures.

\section{REFERENCES}

AVERY, G. T. Notes on reproduction in guinea pigs. Journal of Comparative Psychology, 1925, 5, 373-396.

BARNETT, S. A. An analysis of social behavior in wild rats. Proceedings of the Zoological Society of London, 1958. 130. 107-152.

BARNETT, S. A., \& STODDART, R. C. Effects of breeding in captivity on conflict among wild rats. Journal of Mammalogy, 1969, 50, 321-325.

BEACH, F A. Comparison of copulatory behavior of male rats raised in isolation, cohabitation, and segregation. Journal of Genetic Psychology, 1942a, 60, 121-136.

BEACH, F. A. Analysis of the stimuli adequate to elicit mating behavior in the sexually inexperienced male rat. Journal of Comparative Psychology, 1942b, 33, 163-207.

BROWN, R. H. Stability of conditioning and sexual dominance in the rabbit. Science, $1937,86,520$.

CALHOUN, J. B. A "behavioral sink." In E. L. Bliss (Ed.)., Roots of behavior. New York: Harper, 1962. Pp. 295-315.

DRORI, D., \& FOLMAN, Y. The sexual behavior of males unmated to sixteen months of age. Animal Behaviour, 1967. 15, 20-24.

FOLMAN, Y., \& DRORI, D. Normal and abberant copulatory behavior in male rats ( $R$. norvegicus) reared in isolation. Animal Behaviour, 1965, 13, 427-429.

FULLER, J. L., \& DUBOIS, E. M. The behavior of dogs. In E. S. E. Hafez (Ed.), The behavior of domestic animals. Baltimore: Williams \& Wilkins, 1962. Pp. 415-452.

GERALL, H. D., WARD, I., \& GERALL, A. Disruption of the male rat's sexual behavior induced by social isolation. Animal Behaviour, 1967, 15, 54-58.

GRANT, E. C. An analysis of thy social behavior of the male laboratory rat. Behaviour, 1963, 21, 260-281.

GRANT, E. C. \& MACKINTOSH, J. H. A comparison of the social postures of some common laboratory rodents. Behaviour, $1963,21,246-259$.

HAFEZ, E. S. E., SUMPTION, L. J., \& JAKWAY, J, $S$. The behavior of swine. In E. S. E. Hafez (Ed.), The behavior of domestic animals. Baltimore: Williams \& Wilkins, 1962. Pp. 334-369.

JENKINS, $M$. The effect of segregation on the sexual behavior of the white rat as measured by the obstruction method. Genetic Psychology Monographs, 1928 , 3, 457-471.

KEMPF, E. J. The social and sexual behavior of the infra human primates with some comparable facts in human behavior. Psychoanalytic Review, 1917. 4, 127-154.

KINSEY, A. C., POMEROY, W. B., MARTIN, C. E., \& GEBHARD, 0.0 Sexual behavior in the human female. Philadelphia: Saunders, 1953.

LOGAN, F. A., \& BOICE, R, Aggressive behavior of paired rodents in an avoidance context. Behaviour, 1969. 34. 161-183.

LOUTITT, C. M. Reproductive behavior of the guinea pig. I. The normal mating behavior. Journal of Comparative Psychology, 1927, 7, 247-263.

REYNIERSE, J. H. Submissive postures during shock-elicited aggression. Animal Behaviour, in press.

STONE, C. P. The congenital sexual behavior of the young male albino rat. Journal of Comparative Psychology $1922,2,95+153$. 